\title{
Improvements in quench factor modelling
}

\author{
P.A. Rometsch, M.J. Starink and P.J. Gregson \\ Materials Research Group, School of Engineering Sciences, \\ University of Southampton, Southampton S017 1BJ, UK
}

\begin{abstract}
In this contribution, the validity of a number of key quench factor analysis (QFA) assumptions is discussed. It is shown that the incorporation of a square-root dependency of yield strength on precipitate volume fraction provides a sounder physical basis for quench factor modelling. Peakaged strength/hardness prediction accuracies are not affected, but $\mathrm{C}$-curve positions are. It is also demonstrated that transformation kinetics are described more correctly by a modified StarinkZahra equation than by a Johnson-Mehl-Avrami-Kolmogorov type equation, yielding better prediction accuracies when a physically realistic Avrami exponent of 1.5 or greater is used. Finally, a regular solution model is introduced to quantify the influence of the solute solubility temperature dependency on the minimum strength. These improvements are all implemented within the framework of classical QFA.
\end{abstract}

\section{INTRODUCTION}

Quench factor analysis (QFA) was first developed by Evancho and Staley [1] in the early 1970s to predict the effect of continuous cooling quench rate on the yield strength and corrosion resistance of wrought aluminium alloys. A theoretical justification was proposed by Staley [2] in 1987, and an improved quench factor model, which includes the capability to make fracture toughness predictions, was published in 1993 [3].

Since its development, QFA has been applied to a wide range of wrought aluminium alloys to predict properties and/or optimise industrial quenching procedures [4-12]. It has also been applied to steels [13-14] and aluminium casting alloys [15-16], and is now recognised as an important technique for modelling property losses during continuous cooling [17-19]. 
The key foundational principle of QFA is the use of isothermal transformation kinetics to predict transformation behaviour during continuous cooling. By representing a quenching curve as a series of consecutive isothermal transformation events and adding together the amount transformed during each isothermal step, the effect of temperature on transformation rate can be taken into account for virtually any step quenching or continuous cooling thermal path. Consequently, the effect of quench rate on properties can be modelled much more accurately than if an average quench rate approach is taken [1].

The use of isothermal data to make non-isothermal transformation predictions dates back to Scheil [20] and Avrami [21], who proposed that this is only possible for a very limited number of additive reactions. Cahn [22] later showed that transformations which nucleate heterogeneously (as is typically observed during quenching of aluminium alloys) tend to obey the rule of additivity, suggesting that a wide range of reactions are additive. Since then, a broad range of non-isothermal transformations have been successfully modelled under the assumption that the reactions are additive [23-30], despite the fact that the precise conditions for additivity are still disputed [31-35].

Although the success of QFA suggests that transformations occurring during quenching are largely additive, there is still a lack of conclusive evidence regarding the additivity or nonadditivity of such reactions. Consequently, it must be remembered that this continues to be a major assumption at the heart of QFA. Because of the complex and controversial nature of the subject, however, a detailed discussion of additivity is beyond the scope of this paper. Instead, the purpose of this paper is to draw attention to some of the other assumptions made in QFA, to discuss their limitations and to suggest improvements. These improvements are designed to be used within the existing framework of classical QFA. The suggested QFA improvements are tested by comparing predictions with published data on the strength and hardness of quench sensitive $6 \mathrm{xxx}$ and $7 \mathrm{xxx}$ alloys.

\section{CLASSICAL QUENCH FACTOR ANALYSIS}

\subsection{Theoretical Background}

The equation for the C-curve, or time-temperature-property (TTP) curve, that is used in all versions of QFA is 


$$
C_{t}=-k_{1} k_{2} \exp \frac{k_{3} k_{4}^{2}}{R T\left(k_{4}-T\right)^{2}} \exp \frac{k_{5}}{R T}
$$

where

$$
\begin{aligned}
C_{t}= & \text { critical time required to precipitate a constant amount of non-hardening } \\
& \text { precipitates during isothermal annealing (the locus of which is the C-curve } \\
& \text { corresponding to that fraction transformed), } \\
k_{1}= & \ln (\text { fraction untransformed), } \\
k_{2}= & \text { constant related to the reciprocal of the number of nucleation sites, } \\
k_{3}= & \text { constant related to the energy required to form a nucleus, } \\
k_{4}= & \text { constant related to the solvus temperature, } \\
k_{5}= & \text { constant related to the activation energy for diffusion, } \\
R= & \text { gas constant }=8.3143 \mathrm{JK}^{-1} \mathrm{~mol}^{-1}, \text { and } \\
T= & \text { temperature. }
\end{aligned}
$$

Eq. 1 was derived [2] by taking the reciprocal of the simplified classical nucleation rate equation,

$$
\dot{N}_{\text {het }}=N_{o} \exp \left(-\frac{\Delta G_{\text {het }}^{*}}{R T}\right) \exp \left(-\frac{Q_{d}}{R T}\right)
$$

and, by ignoring elastic coherency strains around nucleated particles, assuming that

$$
\Delta G_{h e t}^{*}=\frac{K_{s} T_{s}^{2}}{\left(T_{s}-T\right)^{2}}
$$

where

$$
\begin{aligned}
& \dot{N}_{h e t}=\text { nucleation rate, } \\
& N_{o}=\text { pre-exponential term related to the number of nucleation sites, } \\
& \Delta G_{h e t}^{*}=\text { activation energy for heterogeneous nucleation, } \\
& Q_{d} \quad=\text { activation energy for diffusion, } \\
& K_{s} \quad=\text { constant related to the free energy change of nucleus formation, } \\
& T_{s} \quad=\text { solvus temperature, and } \\
& T_{s}-T=\text { degree of undercooling. }
\end{aligned}
$$

Based on the C-curve and a continuous cooling quench curve, the quench factor is defined by

$$
Q=\int_{t_{o}}^{t_{f}} \frac{d t}{C_{t}} \approx \sum_{i=1}^{n} \frac{d t_{i}}{C_{t, i}}
$$


where

$$
\begin{aligned}
& \mathrm{Q} \quad=\text { quench factor, } \\
& d t \quad=\text { time increment from the quench curve, } \\
& t_{o} \quad=\text { time at start of quench, and } \\
& t_{f} \quad=\text { time at end of quench. }
\end{aligned}
$$

By assuming that the transformation kinetics can be described by a Johnson-Mehl-AvramiKolmogorov (JMAK) equation where the Avrami exponent, $n$, equals 1 , and assuming that the strength (or hardness) after peak ageing varies linearly with the amount of solute available for the precipitation of the hardening phase, classical quench factor models predict the variation of strength with quench rate using the following equation:

$$
\frac{\sigma-\sigma_{\min }}{\sigma_{\max }-\sigma_{\min }}=\exp \left(k_{1} Q\right)
$$

where

$$
\begin{array}{ll}
\sigma & =\text { strength attained after peak ageing (T6 condition), } \\
\sigma_{\max } & =\text { maximum T6 strength (attained after an infinitely fast quench), } \\
\sigma_{\min } & =\text { minimum T6 strength (a constant, or temperature-dependent), } \\
k_{1} & =\ln \left(\frac{\sigma_{x}-\sigma_{\min }}{\sigma_{\max }-\sigma_{\min }}\right) \\
\sigma_{x} & =\text { nominal strength represented by the C-curve, and } \\
Q & =\text { quench factor. }
\end{array}
$$

Some authors have assumed $\sigma_{\min }$ to be negligible and have therefore simplified Eq. 5 to:

$$
\frac{\sigma}{\sigma_{\max }}=\exp \left(k_{l} Q\right)
$$

\subsection{Assumptions, Limitations and Inconsistencies}

Classical QFA, as outlined in Section 2.1, contains a range of assumptions, some of which are inconsistent with recent experimental and theoretical findings. In particular, the following points are highlighted: 


\section{A. Strength varies linearly with solute concentration}

The theories of yield strength development based on the blocking of dislocation movement by obstacles indicate that the strengthening contributions due to both shearable and non-shearable precipitates are proportional to the square root of the precipitate volume fraction, regardless of whether Friedel or Kocks statistics are used [36-39]. This theoretical finding has been confirmed experimentally and incorporated into successful models on strengthening in a wide range of alloys [40-45]. Classical quench factor analysis, however, contradicts this often-used theoretical result by assuming that the strength varies linearly with the amount of solute available for precipitation hardening.

\section{B. Transformation kinetics are described by a special case of the JMAK equation where $n=1$} When Evancho and Staley [1] analysed 7075-T6 and 2024-T4 interrupted quenching data from Fink and Willey [46] and McAlevy [47], they obtained linear correlations with a slope of 1 on $\operatorname{logarithmic}$ plots of $-\log \left(\sigma / \sigma_{\max }\right)$ vs isothermal hold time. Ever since then it has been assumed that the Avrami exponent ( $n$ ) equals 1 and can therefore be omitted from Eqs. 5 and 6, regardless of what material the QFA is being applied to. However, the diffusion-controlled nucleation and growth theories indicate that $n<1.5$ is not possible for reactions that involve growth through diffusion in 3 dimensions (e.g. precipitates nucleating and growing within grains) [48-50]. Hence the use of $n=1$ in classical QFA contradicts the notion that quench sensitivity is mostly related to the formation of non-hardening precipitates within grains during quenching. Although Staley [2] acknowledged that $n$ can vary with nucleation rate and precipitate morphology, no steps were taken to at least include it as a variable in Eqs. 5 and 6.

In addition, Starink [50] has clearly demonstrated that the JMAK equation itself often does not describe diffusion-controlled precipitation reactions adequately. This highlights another shortcoming in Eqs. 5-6: besides assuming that $n=1$, these equations also assume that impingement of diffusion fields (i.e. soft impingement) can be described by the JMAK equation, which is valid for hard impingement but has not been proven for soft impingement [50-51]. While the JMAK equation may be valid for relatively rapid quenches yielding limited amounts of widely spaced precipitates, there could be numerous instances (e.g. during slow cooling, long isothermal holds or for a high number density of nucleation sites) where impingement becomes important.

\section{The minimum strength in the Avrami equation}


By neglecting the minimum strength, $\sigma_{\min }$, it is evident that Eq. 6 loses accuracy as $\sigma / \sigma_{\max }$ decreases. From this point of view, predictions at lower values of $\sigma / \sigma_{\max }$ are improved by introducing $\sigma_{\min }$ as a constant related to the alloy strength in the absence of hardening precipitates. For most commercial alloys and heat treatments, the assumption that $\sigma_{\min }$ is a constant is adequate because only predictions at high values of $\sigma / \sigma_{\max }$ are generally of interest. If the quench factor model is calibrated with continuous cooling data rather than interrupted quenching data, then $\sigma_{\min }$ is readily defined as a constant equivalent to the T6 strength attained after an infinitely slow quench.

However, in an analysis of interrupted quenching data from an Al-Cu-Li alloy, Staley et al [3] found that $\sigma_{\min }$ varies strongly with the isothermal hold temperature. Consequently, they improved their quench factor model by introducing an empirically determined parabolic variation of $\sigma_{\min }$ with temperature, where $\sigma_{\min }$ was defined as the minimum T6 strength resulting from infinite holding at a given isothermal hold temperature. The parabolic variation of $\sigma_{\min }$ with temperature was due to two main effects: (a) the sloping solvus and (b) the precipitation of a hardening phase at the lower isothermal hold temperatures. This, however, was an alloy-specific empirical approximation; a more rigorous way of dealing with the uncertainties surrounding $\sigma_{\min }$ would be to include a regular solution model to describe the effects of the sloping solvus.

\section{Other considerations}

It is well established that the decomposition kinetics during ageing (at least in the early stages) are strongly influenced by the concentration of quenched-in vacancies and vacancy-related defects, which in turn are determined mainly by the quench temperature, quench rate and alloy chemistry [52-59]. In general, ageing kinetics are increased by faster quenching rates or by quenching from higher temperatures. Consequently, it must be considered in QFA that a given ageing treatment designed to produce peak strength after water quenching will, in general, correspond to an underaged condition after a very slow air cool, leading to possible errors in QFA predictions. However, since most quench factor models are only concerned with a relatively small range of industrially relevant quenching rates at high values of $\sigma / \sigma_{\max }$, and the ageing curves of many commercial alloys have relatively broad peaks, it may be justifiable to disregard variations in ageing kinetics in some cases (see e.g. [60]). For Al-Mg-Si alloys there is some evidence that ageing kinetics are accelerated by increased quench rates and higher quench temperatures [61-63]. A method for taking account of such altered precipitation kinetics is presented elsewhere [11]. 
As an additional point, it is suggested that the convenient practice of substituting hardness for strength values in QFA and related equations (see, e.g. [10, 12, 41, 64]), be approached with caution. Although good linear correlations between hardness and strength may be obtained if the same ageing treatment is applied after different continuous cooling quench rates, differences in strain hardening generally lead to poor correlations if different ageing treatments are used [6566]. Uncertainties may be overcome by including an existing hardness-strength conversion method based on differences in strain hardening [66-67] in the quench factor model.

Finally, caution must be exercised when calibrating models (like the current one) that contain a large number of adjustable parameters. The large number of adjustable parameters requires a large and well-distributed dataset if each parameter is to be determined accurately and unambiguously. For example, if a quench factor model is calibrated only with continuous cooling data from 10 different quench rates, several combinations of $k_{2}$ to $k_{5}$, can give equally good fits. Additional work (not presented here) has shown that different sets of $k_{2}$ to $k_{5}$ values yielding similar fits to data can result in dramatically different C-curves. This problem can be partly overcome by using a larger and more well-distributed dataset. Including some interrupted quenching data with the continuous cooling data can be a particularly effective way of pinpointing C-curve positions. Further inaccuracies may result from the fact that QFA models are based on single C-curves, whereas in many commercial alloys more than one phase may actually precipitate during quenching. While multiple $\mathrm{C}$-curves could be predicted to address this issue, such work may complicate the analysis unnecessarily.

One general conclusion from Section 2.2 is that C-curves derived from a QFA of strength/hardness data can deviate significantly from time-temperature-transformation (TTT) curves determined more directly from data based on the extent of reactions. Having identified several of the assumptions and inconsistencies in classical QFA, it will be demonstrated in the next section that the model can be improved and that some of the inconsistencies can be resolved. As the considerations under point $\mathrm{D}$ have been addressed to some extent elsewhere [11, 66-67], this contribution will focus only on points A, B and C. 


\section{IMPROVEMENTS IN QUENCH FACTOR ANALYSIS}

In this section, suggestions for improving classical QFA theory and practice are made and the implications are considered by examining predictions made using data on the influence of interrupted quenching and continuous cooling on T6 strength and hardness. The nature and source of the data are described in Table 1.

\subsection{Variation of strength with solute concentration}

As outlined under point $\mathrm{A}$ in Section 2.2, the assumption that the strength after peak ageing varies linearly with solute concentration after quenching is inconsistent with strengthening theory. To resolve this inconsistency, Eq. 5 should therefore be re-written as:

$$
\frac{\sigma-\sigma_{\min }}{\sigma_{\max }-\sigma_{\min }}=\left[\exp \left(k_{1} Q\right)\right]^{1 / 2}
$$

To illustrate the different predictions made by Eqs. 5 and 7, these equations, together with Eqs. 1 and 4, were fitted to Fink and Willey's data [46] by iteratively adjusting constants $k_{2}$ to $k_{5}, \sigma_{\max }$ and $\sigma_{\min }$ to minimise the root mean squared error (RMSE) ${ }^{1}$. It is noted from Fig. 1(a) that the difference between the two results can be as large as 80-90 MPa at intermediate quench factors. However, optimisation of the models by iterative variation of the parameters in Eq. 1 results in both Eq. 5 and Eq. 7 predicting similar strengths i.e. different TTP curves are predicted to compensate for the differences between the two equations (Fig 1(b)). While the TTP curve predicted by Eq. 5 (with its nose at about $0.1 \mathrm{sec}$ ) is similar to that determined from the same data by Evancho and Staley [1] using classical QFA, it is expected that the TTP curve predicted by Eq. 7 (with its nose at about $0.05 \mathrm{sec}$ ) is more true to reality.

Although Staley [2] has shown mathematically that Eq. 6 remains valid regardless of whether the square root of the volume fraction is introduced into the equation or not, this is not strictly true. While models can be optimised to predict the same strengths using either Eq. 6 or Eq. 7 (with $\sigma_{\min }=0$ ), the predictions will, as in Fig. 1, result in different TTP curves. Despite similar

\footnotetext{
${ }^{1}$ The RMSE values throughout this paper are calculated from data used to calibrate each model, making them dependent on the model complexity/structure. Since different tables/figures result from different model structures, comparisons of RMSE values can only be made within tables/figures and not between tables/figures.
} 
prediction accuracies, it is expected that Eq. 7 will always result in more physically correct TTP curves than Eqs. 5 or 6.

In conclusion, therefore, an apparent inconsistency in QFA can be resolved by replacing Eq. 5 with Eq. 7 whilst retaining the overall structure of classical QFA. Prediction accuracies of T6 strength/hardness are not affected, but resulting C-curves are believed to be more realistically positioned.

\subsection{Avrami exponents and impingement}

In Section 2.2, point B, it was indicated that the choice of Avrami exponent in classical QFA may be questionable and that possible deviation from classical JMAK-type impingement needs to be considered. To address these issues, the applicability of the following equation, derived by Starink and Zahra [69-72], will now be investigated:

$$
\alpha=1-\left[\frac{(k t)^{n}}{\eta_{i}}+1\right]^{-\eta_{i}}
$$

where $\alpha$ is the fraction transformed, $k$ is a temperature-dependent constant, $n$ is the Avrami exponent, and $\eta_{i}$ is the impingement factor. In the limit of $\eta_{i}$ approaching infinity, Eq. 8 is identical to the JMAK equation. When $\eta_{i}$ is small $\left(\eta_{i}<10\right)$, however, the fraction transformed will differ significantly from that predicted by the JMAK equation, especially in the latter stages of a transformation, where soft impingement may be expected to occur. By adapting Eq. 8 to QFA, Eq. 7 can be replaced by

$$
\frac{\sigma-\sigma_{\min }}{\sigma_{\max }-\sigma_{\min }}=\left[\frac{\left(-k_{l} Q\right)^{n}}{\eta_{i}}+1\right]^{-\eta_{i} / 2}
$$

where the symbols have their usual meanings. A similar equation was used successfully in a recent integrated hardening model of extruded 6082 [11].

The validity of Eq. 9 was tested on interrupted quenching data from Fink and Willey [46] and Bratland $[64,68]$. For $n$-values of 1.0, 1.5 and 2.5, the data were fitted to Eqs. 1, 4 and 9 by iteratively adjusting constants $k_{2}$ to $k_{5}, \sigma_{\max }, \sigma_{\min }$ and $\eta_{i}$ to minimise the RMSE. For $n=1$, the 
lowest RMSE value was always obtained at impingement factors approaching infinity. This corresponds to JMAK kinetics and was approximated by $n=1$ and $\eta_{i}=10^{4}$. Results in Table 2 and Fig. 2 demonstrate that for the 7075 data, $n=1.5$ gives the best results (i.e. the lowest RMSE value). The results in Table 3 and Fig. 3, on the other hand, indicate that for the 6082 data, there is negligible difference in prediction accuracies between the different $n$-values. This difference between the 7075 and 6082 predictions indicates that there may be small but distinct differences in the way these alloys respond to quenching and ageing. However, in general, it may be concluded from these results that the use of $n \geq 1.5$ is likely to result in similar or better prediction accuracies than the use of $n<1.5$.

Besides improved prediction accuracies, the use of $n \geq 1.5$ also ascribes direct physical meaning to the predictions. For example, $n=1.5$ would describe particles of any shape growing through diffusion in 3 dimensions (e.g. within a grain) under conditions where negligible nucleation occurs beyond the initial stages of transformation (i.e. site saturation) [48-50]. Similarly, $n=2.5$ would describe particles of any shape growing through diffusion in 3 dimensions under continuous nucleation conditions [48-50]. Both these scenarios would be compatible with the 6082 predictions in Table 3, as Bratland $[64,68]$ has demonstrated by transmission electron microscopy that non-hardening precipitates nucleate and grow at dispersoids within grains during quenching. On the other hand, $n=1$ is not possible for precipitates growing through diffusion in 3 dimensions (e.g. within a grain) or in 1 dimension (e.g. on a grain boundary), irrespective of whether continuous nucleation or site saturation occurs [48-50].

It should also be pointed out that the range of impingement factors for cases where $n \geq 1.5$ in Tables 2 and 3 is consistent with experimentally determined values ranging from $\eta_{i}=0.5$ to $\eta_{i}=$ 2.2 for a number of different reactions [69-72]. Although $n$ and/or $\eta_{i}$ may vary during industrial quenching operations due to different types/densities of nucleation sites, different types/shapes/spacings of precipitates and changing nucleation rates, the consideration of these poorly understood relationships would unnecessarily complicate the model. Instead, it may be better to make allowance for such influences by determining average values of $n$ and/or $\eta_{i}$ by iteration. In any case, however, it is expected that C-curves predicted with $n<1.5$ may be inaccurate.

In conclusion, the inclusion of a recently derived expression for precipitation kinetics incorporating an adjustable impingement factor has resulted in an improvement to classical QFA. 
Improved accuracies in QFA predictions are generally obtained when Avrami exponents of greater than or equal to 1.5 are used in combination with impingement factors that are consistent with recent experimental and theoretical work.

\subsection{The minimum strength}

A rigorous way of dealing with the variation of the minimum strength with the temperaturedependent solute solubility (point $\mathrm{C}$ in Section 2.2) is to include a regular solution model to describe the sloping solvus. For ternary alloys, the solvus for a precipitate of fixed stoichiometry, $A l_{m} A_{x} B_{y}$, can be conveniently described by $[64,68]$ :

$$
\left[C_{A}\right]^{x}\left[C_{B}\right]^{y}=\exp \left(\frac{\Delta S^{o}}{R}\right) \exp \left(\frac{-\left(\Delta H^{o}-x \Omega\right)}{R T}\right)
$$

It further holds that:

$$
\left[C_{B}\right]=C_{B}^{o}-\frac{y M_{B}}{x M_{A}}\left(C_{A}^{o}-\left[C_{A}\right]\right)
$$

where $\quad\left[C_{A, B}\right]=$ equilibrium matrix concentrations (wt $\left.\%\right)$ of elements $\mathrm{A}$ and $\mathrm{B}$,

$C_{A, B}^{o} \quad=$ nominal concentrations ( $\mathrm{wt} \%$ ) of elements $\mathrm{A}$ and $\mathrm{B}$ in the alloy,

$x, y, m=$ integers describing the stoichiometry of the compound $A l_{m} A_{x} B_{y}$,

$M_{A}, M_{B}=$ atomic weights of elements $\mathrm{A}$ and $\mathrm{B}$,

$\Delta S^{o} \quad=$ standard entropy of reaction,

$\Delta H^{o} \quad=$ standard enthalpy of reaction,

$\Omega \quad=$ contribution of interface curvature to reaction enthalpy (a function of the precipitate-matrix interfacial energy and the precipitate molar volume and radius; typically $\Omega=0$ for equilibrium precipitates),

$R \quad=$ gas constant, and

$T \quad=$ solvus temperature.

The composition achieved after complete precipitation at a fixed temperature, $T$, is described by the combination of Eqs. 10 and 11. Analytical solutions for this combination can be obtained for specific $x$ : $y$ ratios (e.g. for $\mathrm{Mg}_{2} \mathrm{Si}$, the use of $x=2 y$ gives an analytically solvable cubic equation). For a 6082 alloy, stable $(\beta)$ and metastable ( $\beta$ ") solvus boundaries calculated in this manner (assuming $\mathrm{Mg}_{2} \mathrm{Si}$ stoichiometry for both precipitates) are illustrated schematically in Fig. 4. 
Superimposed on this schematic phase diagram are 2 hypothetical interrupted quenches performed so that quench 1 results in an as-quenched $\mathrm{Mg}$ concentration of $C_{A Q 1}$ and quench 2 results in an as-quenched $\mathrm{Mg}$ concentration of $C_{A Q 2}$ (in solid solution). The minimum $\mathrm{Mg}$ concentration, $C_{\min (T)}$, at the isothermal hold temperature, $T_{I H}$, is then given by the equilibrium concentration of $\mathrm{Mg}$ in solid solution at that temperature. If the strength is measured and modelled in the peak-aged (T6) condition and if $\beta$ " is the hardening precipitate in the T6 condition [73], then it is evident from Fig. 4 that quench 1 results in $\mathrm{Mg}$ precipitating to form the hardening $\beta$ " phase (the amount of $\mathrm{Mg}$ precipitating equals $C_{A Q I}-C_{A T}$, where $C_{A T}$ is the amount of $\mathrm{Mg}$ in solution at the ageing temperature, $T_{A}$ ), whereas quench 2 causes insufficient $\mathrm{Mg}$ to be available for precipitation hardening. Using concepts from the Shercliff and Ashby [41] age hardening model and the well established finding that the precipitation strengthening contribution varies with the square root of the precipitate volume fraction (see Sections 2.2A and 3.1 ), it follows that if

$$
\sigma=\sigma_{i}+\Delta \sigma_{s s}+\Delta \sigma_{p p t}
$$

then for $C_{\min (T)}>C_{A T}$ :

$$
\sigma_{\min (T)}=\sigma_{i}+c_{1} C_{A T}^{2 / 3}+c_{2}\left(C_{\min (T)}-C_{A T}\right)^{1 / 2}
$$

and for $C_{\min (T)} \leq C_{A T}$ :

$$
\sigma_{\min (T)}=\sigma_{i}+c_{l} C_{\min (T)}{ }^{2 / 3}
$$

Similarly,

$$
\sigma_{\max (T)}=\sigma_{i}+c_{1} C_{A T}^{2 / 3}+c_{2}\left(C_{\max (T)}-C_{A T}\right)^{1 / 2}
$$

where

$$
\begin{array}{ll}
\sigma_{i}= & \text { intrinsic yield strength of the base metal, } \\
\Delta \sigma_{s s}= & \text { solid solution hardening contribution to the } \mathrm{T} 6 \text { yield strength, } \\
\Delta \sigma_{p p t}= & \text { precipitation hardening contribution to the } \mathrm{T} 6 \text { yield strength, } \\
C_{\min (T)}= & \text { equilibrium solute concentration at the isothermal hold temperature, } \\
C_{\max (T)}= & \text { equilibrium solute concentration at the solution treatment temperature } \\
& \text { (just prior to quenching), and } \\
c_{1}, c_{2}= & \text { constants. }
\end{array}
$$

The yield strength, $\sigma$, may then be predicted using

$$
\frac{\sigma-\sigma_{\min (T)}}{\sigma_{\max (T)}-\sigma_{\min (T)}}=\left[\frac{\left(-k_{l} Q\right)^{n}}{\eta_{i}}+1\right]^{-\eta_{i} / 2}
$$


Eqs. 10-16 are readily applied to interrupted quenching data by calculating $\sigma_{\min (T)}$ for each isothermal hold temperature and $\sigma_{\max (T)}$ for the solution treatment temperature. For continuous cooling data, however, $\sigma_{\min (T)}$ and $\sigma_{\max (T)}$ need to be calculated separately for each of the incremental isothermal steps describing the continuous cooling curve. While $\sigma_{\min (T)}$ is a function of the equilibrium concentration at each incremental isothermal hold temperature (Eqs. 13-14), $\sigma_{\max (T)}$ is a function of solution treatment temperature for the first incremental isothermal step only. For each subsequent incremental isothermal step, $\sigma_{\max (T)}$ is a function of the amount transformed during the previous incremental isothermal step (i.e. $\sigma_{\max (T)}$ is set to equal the predicted value of $\sigma$ from the previous isothermal step). The final cumulative value of $\sigma$ is then taken as the predicted $\mathrm{T} 6$ yield strength for that particular continuous quench.

Alternatively, the analysis can be improved by eliminating the minimum strength altogether and replacing strengths in Eq. 16 with concentrations:

$$
\frac{C_{A Q}-C_{\min (T)}}{C_{\max (T)}-C_{\min (T)}}=\left[\frac{\left(-k_{1} Q\right)^{n}}{\eta_{i}}+1\right]^{-\eta_{i}}
$$

where $C_{A Q}$ is the solute concentration remaining in solution immediately after the quench, and all the other symbols have their usual meanings. Predicted $C_{A Q}$ values may then be converted into T6 yield strengths using:

$$
\begin{array}{cc}
\sigma_{T 6}=\sigma_{i}+c_{1} C_{A T}{ }^{2 / 3}+c_{2}\left(C_{A Q}-C_{A T}\right)^{1 / 2} & \left(\text { for } C_{A Q}>C_{A T}\right) \\
\sigma_{T 6}=\sigma_{i}+c_{1} C_{A Q}{ }^{2 / 3} & \left(\text { for } C_{A Q} \leq C_{A T}\right)
\end{array}
$$

The use of Eqs. 17-19 makes the model more transparent and eliminates uncertainties regarding changes in solid solution strengthening. In Eqs. 7, 9 and 16, for example, $\sigma_{\min }$ or $\sigma_{\min (T)}$ are assumed to contain a constant amount of solid solution strengthening, which could lead to additional errors if there are differences in the amount of solid solution strengthening from quench to quench.

The validity of Eqs. 10-19 was tested on the combined interrupted quenching and continuous cooling data from Bratland [68]. For $n$-values of 1.5, the data were fitted to Eqs. 1, 4 and 10-16 as well as to Eqs. 1, 4, 10-11 and 17-19 by iteratively adjusting constants $k_{2}$ to $k_{5}, \eta_{i}, H V_{i}, c_{1}, c_{2}$ and 
$\Omega$ to minimise the RMSE (using $\Delta H^{o}=95.9 \mathrm{kJmol}^{-1}$ and $\Delta S^{o}=112 \mathrm{JK}^{-1} \mathrm{~mol}^{-1}$ after Bratland [64, 68]). The results, including a scenario where $C_{\min }=0$ for comparison, are presented in Table 4 and in Figs. 5-6.

Table 1: Nature and source of aluminium alloy data used to test improvements in QFA.

\begin{tabular}{|c|c|c|c|c|c|}
\hline $\begin{array}{l}\text { Alloy and } \\
\text { Condition }\end{array}$ & $\begin{array}{l}\text { Data } \\
\text { Type }\end{array}$ & $\begin{array}{c}\text { Number of } \\
\text { Datalines }\end{array}$ & $\begin{array}{c}\text { Range of Quenching } \\
\text { Conditions } \\
\end{array}$ & Property & Source \\
\hline $7075-\mathrm{T} 6$ & $\begin{array}{l}\text { Interrupted } \\
\text { quenching }\end{array}$ & 40 & $\begin{array}{c}427^{\circ} \mathrm{C}, 316^{\circ} \mathrm{C}, 260^{\circ} \mathrm{C} \text { and } \\
204^{\circ} \mathrm{C}(1 \text { to } 480 \mathrm{sec} \\
\text { holding times })\end{array}$ & $\begin{array}{c}\text { Yield } \\
\text { Strength }\end{array}$ & $\begin{array}{c}\text { Fink and } \\
\text { Willey [46] }\end{array}$ \\
\hline $\begin{array}{l}6082-\mathrm{T} 6 \\
\text { A1 (580) }\end{array}$ & $\begin{array}{l}\text { Interrupted } \\
\text { quenching }\end{array}$ & 64 & $\begin{array}{c}400^{\circ} \mathrm{C}, 375^{\circ} \mathrm{C}, 350^{\circ} \mathrm{C}, \\
325^{\circ} \mathrm{C}, 300^{\circ} \mathrm{C}, 275^{\circ} \mathrm{C}(10 \\
\text { to } 600 \mathrm{sec} \text { holding times })\end{array}$ & $\begin{array}{l}\text { Vickers } \\
\text { Hardness }\end{array}$ & $\begin{array}{c}\text { Bratland } \\
\text { [68] }\end{array}$ \\
\hline $\begin{array}{l}6082-\mathrm{T} 6 \\
\mathrm{~A} 1(580)\end{array}$ & $\begin{array}{c}\text { Continuous } \\
\text { cooling }\end{array}$ & 10 & $\begin{array}{l}10 \text { linear quench rates } \\
\text { from } 1 \text { to } 35^{\circ} \mathrm{C} / \mathrm{sec}\end{array}$ & $\begin{array}{c}\text { Vickers } \\
\text { Hardness }\end{array}$ & $\begin{array}{c}\text { Bratland } \\
\text { [68] }\end{array}$ \\
\hline
\end{tabular}

Table 2: Results from fitting interrupted quenching data from Fink and Willey [46] to Eq. 9.

\begin{tabular}{|c|c|c|c|}
\hline Scenario & $\boldsymbol{n}$ & $\boldsymbol{\eta}_{\boldsymbol{i}}$ & RMSE \\
\hline A & 1.0 & $10^{4}$ & $8.1 \mathrm{MPa}$ \\
\hline B & 1.5 & 4.1 & $5.4 \mathrm{MPa}$ \\
\hline C & 2.5 & 0.9 & $8.6 \mathrm{MPa}$ \\
\hline
\end{tabular}

Table 3: Results from fitting interrupted quenching data from Bratland [68] to Eq. 9.

\begin{tabular}{|c|c|c|c|}
\hline Scenario & $\boldsymbol{n}$ & $\eta_{\boldsymbol{i}}$ & RMSE \\
\hline $\mathrm{A}$ & 1.0 & $10^{4}$ & $4.1 \mathrm{HV}$ \\
\hline $\mathrm{B}$ & 1.5 & 3.0 & $4.0 \mathrm{HV}$ \\
\hline $\mathrm{C}$ & 2.5 & 0.9 & $4.0 \mathrm{HV}$ \\
\hline
\end{tabular}

Table 4: Results from fitting interrupted quenching data from Bratland [68] to Eqs. 16 and 17 for $n$-values of 1.5.

\begin{tabular}{|c|c|c|c|}
\hline Scenario & Equation & $\eta_{\boldsymbol{i}}$ & RMSE \\
\hline $\mathrm{A}$ & 16 & 2.8 & $3.5 \mathrm{HV}$ \\
\hline $\mathrm{B}$ & $16\left(C_{\min }=0\right)$ & 2.5 & $3.9 \mathrm{HV}$ \\
\hline $\mathrm{C}$ & 17 & 1.4 & $4.9 \mathrm{HV}$ \\
\hline
\end{tabular}


Fig. 5 illustrates how $C_{\min (T)}$ and $H V_{\min (T)}$ vary with temperature. The rapid increase in $H V_{\min (T)}$ above about $395^{\circ} \mathrm{C}\left(T_{t}\right)$ is due to the precipitation hardening contribution that occurs when $C_{\min (T)}>C_{A T}$. At lower temperatures, the variation of $H V_{\min (T)}$ with temperature is relatively small since it is only influenced by changes in solid solution hardening. In this case, there is only a negligibly small slope in $H V_{\min (T)}$ at temperatures below $T_{t}$, suggesting that the use of Eq. 16 (instead of Eq. 17) is justified. For alloys with significant amounts of solid solution hardening, however, Eq. 17 is expected to give better results than Eq. 16.

The results in Table 4 indicate that for predictions made using Eq. 16 with $n=1.5(n=1.5$ was found to give the best RMSE values), there is little difference in prediction accuracies between using $C_{\min (T)}=0$ and allowing $C_{\min (T)}$ to vary with temperature. Predicted TTP curves for scenarios A and B are also very similar (Fig. 6). It may be inferred from this analysis that the benefits of allowing $C_{\min (T)}$ to vary with temperature are only realised in cases where (a) $C_{\min (T)}>C_{A T}$ and (b) the TTP curve is positioned such that a significant amount of transformation will occur at temperatures above the transition temperature, $T_{t}$. In any case, however, the incorporation of Eqs. 10-19 makes the quench factor model more transparent and more widely applicable, making it possible, for example, for variations in ageing temperature, solution treatment temperature and/or composition to be included in the model.

\section{CONCLUSIONS}

The theoretical basis for QFA has been examined. The main assumptions have been highlighted and discussed in relation to their limitations. Suggestions for improvement have been made within the framework of classical QFA. In particular, it is concluded that:

- In comparison with classical QFA, the incorporation of a square-root dependency of yield strength on volume fraction of precipitates gives similar prediction accuracies of T6 strength/hardness but more realistically positioned C-curves.

- Transformation kinetics are described more correctly by a modified Starink-Zahra equation (Eq. 9, 16 or 17) than by a JMAK-type equation (Eq. 5, 6 or 7). Prediction accuracies are improved and gains in physical consistency are achieved when an Avrami exponent of 1.5 or greater is used. 
- The minimum strength ambiguity can be eliminated by including a regular solution model to describe the variation of $C_{\min }$ or $\sigma_{\min }$ with temperature.

Some of the improvements identified will affect the positions of the C-curves derived from QFA, but it is expected that these improvements enable true transformation behaviour during quenching to be described more accurately.

\section{ACKNOWLEDGEMENTS}

The authors would like to thank The Luxfer Group for financial support.

\section{REFERENCES}

1. J. W. Evancho, J. T. Staley, Metall. Trans. 5 (1974) 43.

2. J. T. Staley, Mater. Sci. Tech. 3 (1987) 923.

3. J. T. Staley, R. D. Doherty, A. P. Jaworski, Metall. Trans. 24A (1993) 2417.

4. C. E Bates, G. E. Totten, Heat Treat. Metals, 15 (1988) 89.

5. J.-S. Kim, R. C. Hoff, D. R. Gaskell, Proceedings of the International Symposium on Materials Processing in the Computer Age, The Minerals, Metals and Materials Society, New Orleans, 1991, p. 203.

6. J. T. Staley, Proceedings of the Third International Conference on Aluminium Alloys, The Norwegian Institute of Technology, Trondheim, 1992, p. 107.

7. C. E. Bates, AFS Trans. 101 (1993) 1045.

8. J. T. Staley, Proceedings of the International Conference on Computer-Assisted Materials Design and Process Simulation, ISIJ, Tokyo, 1993, p. 237.

9. N. Järvstråt, S. Tjøtta, Metall. Mater. Trans. 27B (1996) 501.

10. D. D. Hall, I. Mudawar, R. E. Morgan, S. L. Ehlers, J. Mater. Eng. Perform. 6 (1997) 77.

11. P. A. Rometsch, M. J. Starink, P. J. Gregson, Proceedings of the James T. Staley Honorary Symposium on Aluminum Alloys, Indianapolis, Indiana, November 5-8, 2001, ASM International, Materials Park, in press.

12. J. D. Bernardin, I. Mudawar, Int. J. Heat Mass Transfer, 38 (1995) 863.

13. C. E. Bates, J. Heat Treating, 6 (1988) 27. 
14. C. E. Bates, G. E. Totten, Proceedings of the First International Conference on Quenching and Control of Distortion, ASM International, Materials Park, 1992, p. 33.

15. P. A. Rometsch, G. B. Schaffer, J-Y. Yao, M. J. Couper, Proceedings of the Sixth International Conference on Aluminium Alloys, The Japan Institute of Light Metals, Tokyo, 1998, p. 727.

16. P. A. Rometsch, G. B. Schaffer, Int. J. Cast Metals Res. 12 (2000) 431.

17. C. E. Bates, G. E. Totten, R. L. Brennan, Quenching of steel, in: J. R. Davis (Ed.), ASM Metals Handbook - Heat Treating, vol. 4, ASM International, Materials Park, Ohio, 1991, pp. 67-120.

18. C. R. Brooks, Heat treating of aluminum alloys, in: J. R. Davis (Ed.), ASM Metals Handbook - Heat Treating, vol. 4, ASM International, Materials Park, Ohio, 1991, pp. 841879.

19. H. Y. Hunsicker, Aluminum - properties and physical metallurgy, in: J.E. Hatch (Ed.), ASM, Metals Park, Ohio, 1984, pp. 134-199.

20. E. Scheil, Arch. Eisenhüttenwes. 8 (1934) 565.

21. M. Avrami, J. Chem. Phys. 8 (1940) 212.

22. J. W. Cahn, Acta Metall. 4 (1956) 572.

23. M. B. Kuban, R. Jayaraman, E. B. Hawbolt, J. K. Brimacombe, Metall. Trans. 17A (1986) 1493.

24. C. Verdi, A. Visintin, Acta Metall. 35 (1987) 2711.

25. S. H. Park, S. Yue, J. J. Jonas, Metall. Trans. 23A (1992) 1641.

26. T. T. Pham, E. B. Hawbolt, J. K. Brimacombe, Metall. Mater. Trans. 26A (1995) 1987.

27. T. T. Pham, E. B. Hawbolt, J. K. Brimacombe, Metall. Mater. Trans. 26A (1995) 1993.

28. B. I. Bjørneklett, Ø. Grong, O. R. Myhr, A. O. Kluken, Acta Mater. 46 (1998) 6257.

29. Ø. Grong, O. R. Myhr, Acta Mater. 48 (2000) 445.

30. O. R. Myhr, Ø. Grong, Acta Mater. 48 (2000) 1605.

31. I. A. Wierszyłłowski, Metall. Trans. 22A (1991) 993.

32. M. Lusk, H.-J. Jou, Metall. Mater. Trans. 28A (1997) 287.

33. Y. T. Zhu, T. C. Lowe, R. J. Asaro, J. Appl. Phys. 82 (1997) 1129.

34. M. T. Todinov, Metall. Mater. Trans. 29B (1998) 269.

35. Y. T. T. Zhu, T. C. Lowe, Metall. Mater. Trans. 31B (2000) 675.

36. J. W. Martin, Precipitation Hardening, Pergamon Press, Oxford, 1968, pp. 59-76.

37. A. J. Ardell, Metall. Trans. 16A (1985) 2131.

38. E. Nembach, G. Neite, Prog. Mater. Sci. 29 (1985) 177. 
39. A. Deschamps, Y. Bréchet, Acta Mater. 47 (1999) 293.

40. J. C. Huang, A. J. Ardell, Acta Metall. 36 (1988) 2995.

41. H. R. Shercliff, M. F. Ashby, Acta Metall. Mater. 38 (1990) 1789.

42. P. Gomiero, Y. Bréchet, F. Louchet, A. Tourabi, B. Wack, Acta Metall. Mater. 40 (1992) 857.

43. B. C. Lee, J. K. Park, Acta Mater. 46 (1998) 4181.

44. M. J. Starink, P. Wang, I. Sinclair, P. J. Gregson, Acta Mater. 47 (1999) 3855.

45. O. R. Myhr, Ø. Grong, S. J. Andersen, Acta Mater. 49 (2001) 65.

46. W. L. Fink, L. A. Willey, Trans. AIME, 175 (1948) 414.

47. R. B. McAlevy, Master of Science Thesis, Pennsylvania State University, 1965.

48. J. W. Christian, in: R.W. Cahn (Ed.), Physical Metallurgy, North-Holland Publishing Company, Amsterdam, 1965, pp. 443-539.

49. F. L. Cumbrera, F. Sánchez-Bajo, Thermochim. Acta, 266 (1995) 315.

50. M. J. Starink, J. Mater. Sci. 32 (1997) 4061.

51. E.-S. Lee, Y. G. Kim, Acta Metall. Mater. 38 (1990) 1669.

52. W. DeSorbo, H. N. Treaftis, D. Turnbull, Acta Metall. 6 (1958) 401.

53. C. Panseri, T. Federighi, Acta Metall. 8 (1960) 217.

54. D. Turnbull, H. S. Rosenbaum, H. N. Treaftis, Acta Metall. 8 (1960) 277.

55. C. Panseri, T. Federighi, Acta Metall. 11 (1963) 575.

56. T. Federighi, in: R. M. J. Cotterill, M. Doyama, J. J. Jackson, M. Meshii (Eds.), Lattice Defects in Quenched Metals, Academic Press, New York, 1965, pp. 217-268.

57. E. Ozawa, H. Kimura, Acta Metall. 18 (1970) 995.

58. H. Kimura, R. Maddin, Quench Hardening in Metals, North-Holland Publishing Company, Amsterdam, 1971, pp. 20-62.

59. R. Wolter, H.-G. Fabian, P. Czurratis, R. Kroggel, Cryst. Res. Tech. 25 (1990) 177.

60. A. Deschamps, Y. Bréchet, Mater. Sci. Eng. A251 (1998) 200.

61. M. F. Komarova, N. N. Buynov, L. I. Kaganovich, Phys. Metals Metallog. 36 (1974) 72.

62. Y. Song, T. N. Baker, Mater. Sci. Tech. 10 (1994) 406.

63. Y. Song, T. N. Baker, Mater. Sci. Eng. A201 (1995) 251.

64. D. H. Bratland, Ø. Grong, H. Shercliff, O. R. Myhr, S. Tjøtta, Acta Mater. 45 (1997) 1.

65. P. A. Rometsch, PhD Thesis, Department of Mining, Minerals and Materials Engineering, The University of Queensland, 2000.

66. P. A. Rometsch, G. B. Schaffer, Mater. Sci. Eng. A, in press.

67. J. R. Cahoon, W. H. Broughton, A. R. Kutzak, Metall. Trans. 2 (1971) 1979. 
68. D. H. Bratland, PhD Thesis, Department of Metallurgy, The Norwegian Institute of Technology, 1995.

69. M. J. Starink, A.-M. Zahra, Thermochim. Acta, 292 (1997) 159.

70. M. J. Starink, A.-M. Zahra, Phil. Mag. A, 77 (1998) 187.

71. M. J. Starink, C. Y. Zahra, A.-M. Zahra, J. Thermal Anal. 51 (1998) 933.

72. M. J. Starink, J. Mater. Sci. 36 (2001) 4433.

73. A. K. Gupta, D. J. Lloyd, S. A. Court, Mater. Sci. Eng. A301 (2001) 140. 
Eq. $5 \longrightarrow$ Eq. 7

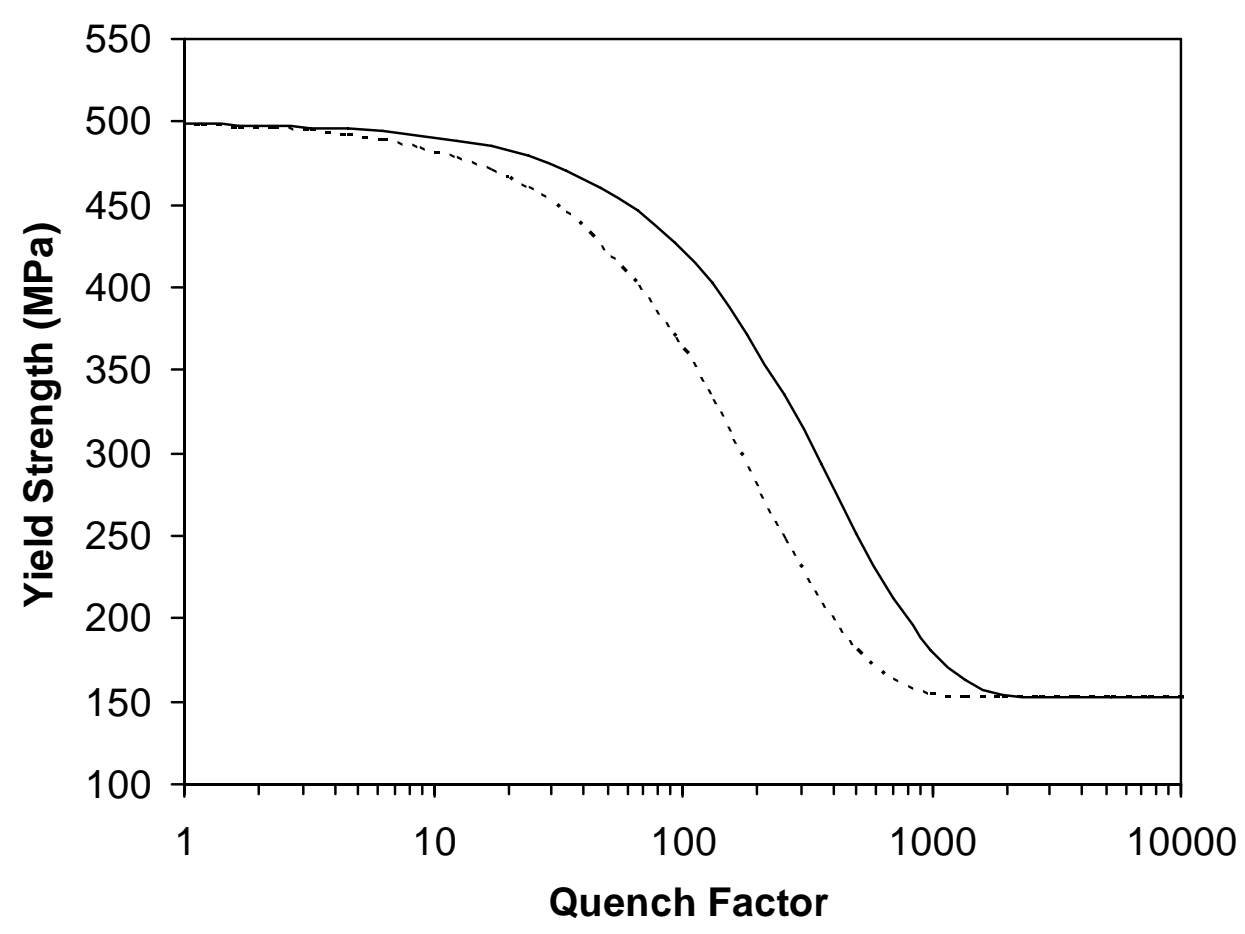

Eq. 5 Eq. 7

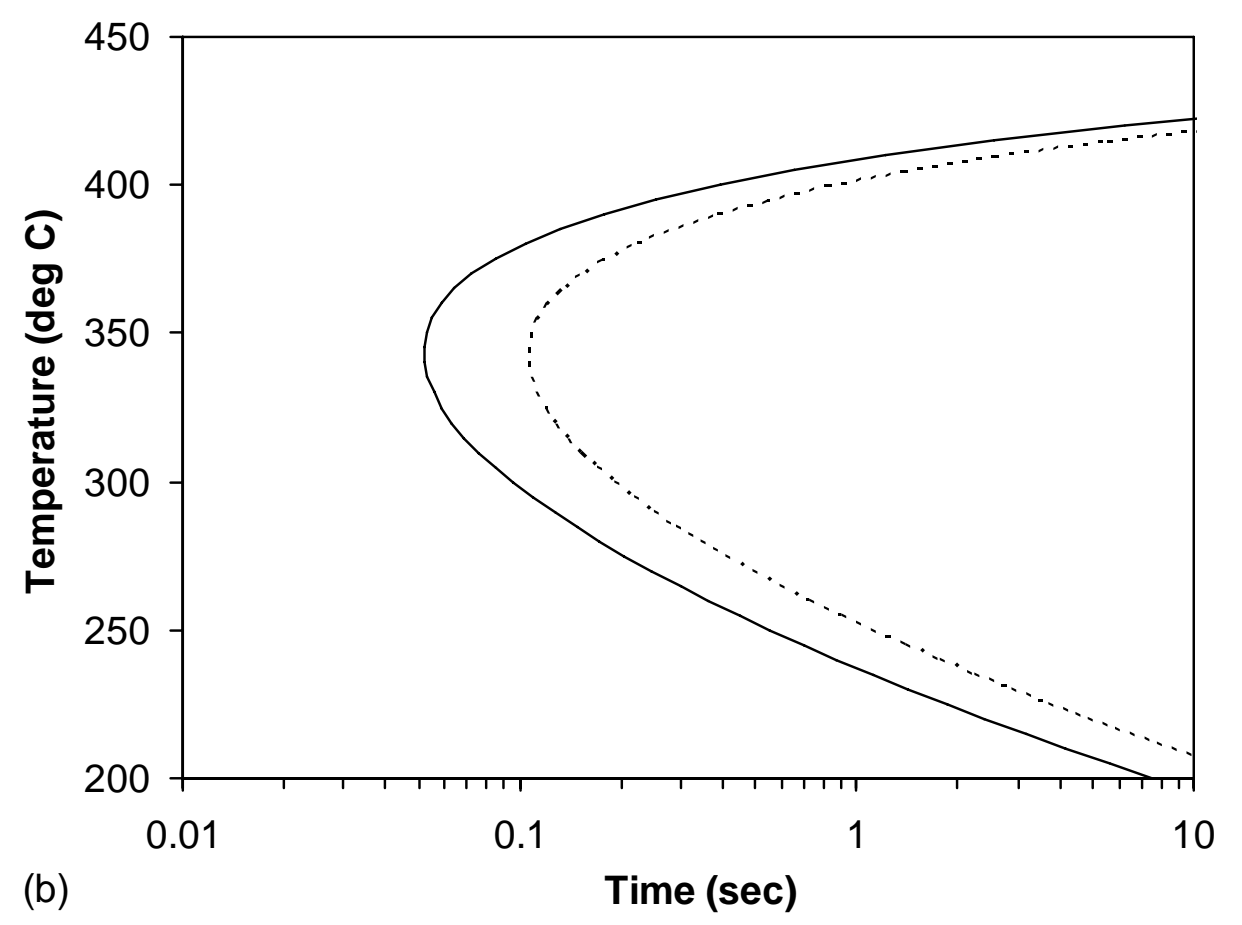

Figure 1: (a) Yield strength vs quench factor curves corresponding to (b) $99.5 \%$ of maximum yield strength TTP curves, determined by fitting isothermal 7075 data from Fink and Willey [46] to Eqs. 5 and 7. The RMSE for both Eq. 5 and Eq. 7 is $8.1 \mathrm{MPa}$. 


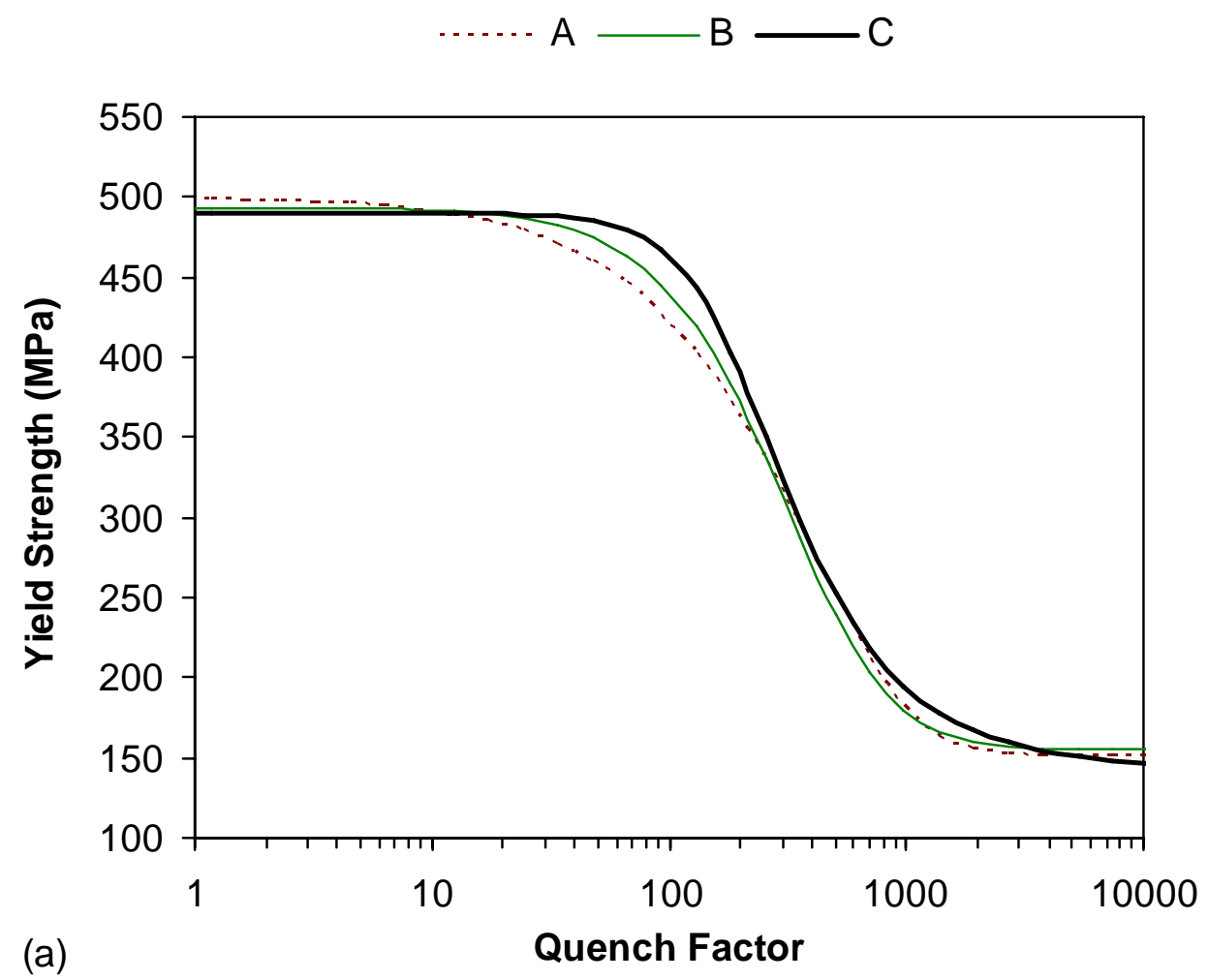

$A-B-C$

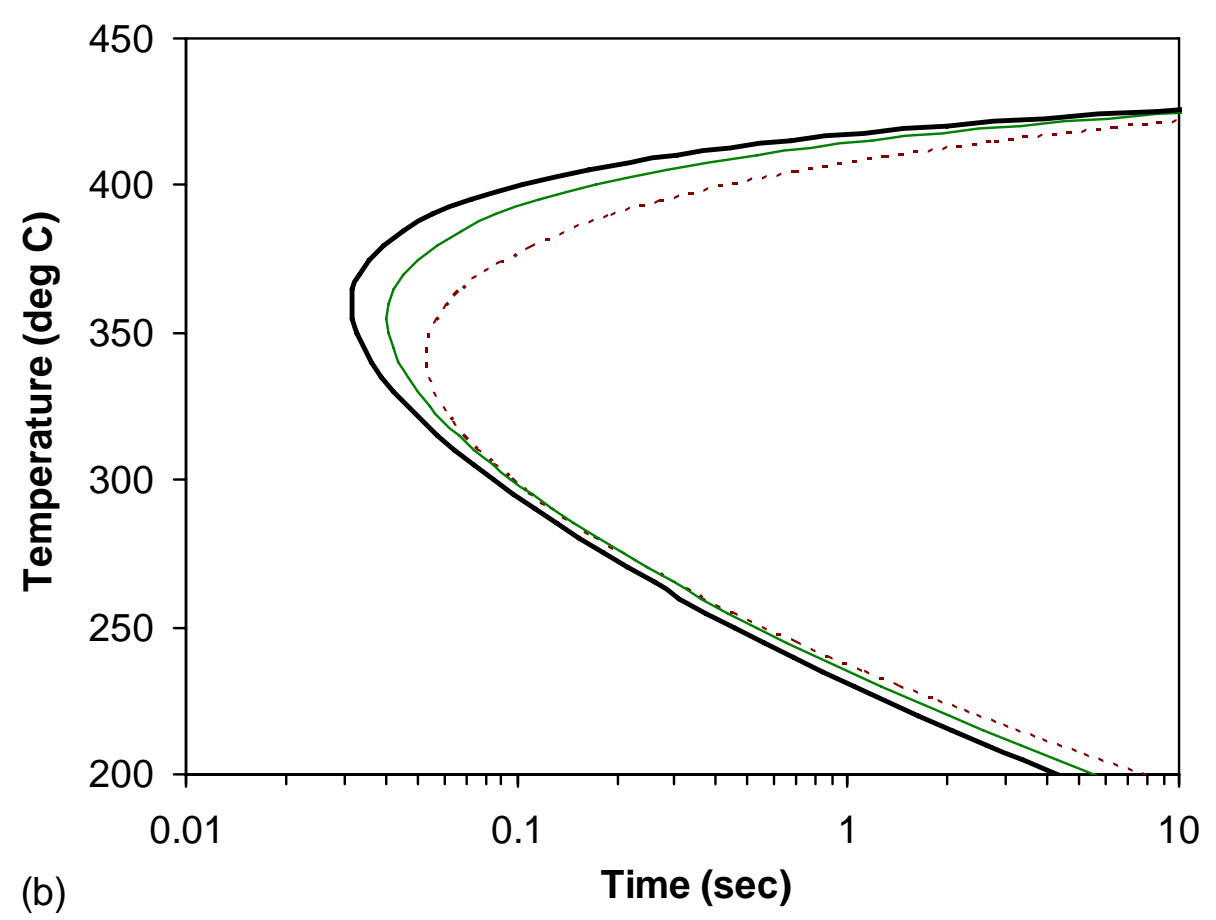

Figure 2: (a) Yield strength vs quench factor curves corresponding to (b) $99.5 \%$ of maximum yield strength TTP curves, determined by fitting isothermal 7075 data from Fink and Willey [46] to Eq. 9 for scenarios where $n=1$ (A), $n=1.5$ (B) and $n=2.5(\mathrm{C})$. Further details are given in Table 2. 
$A-B+C+D$

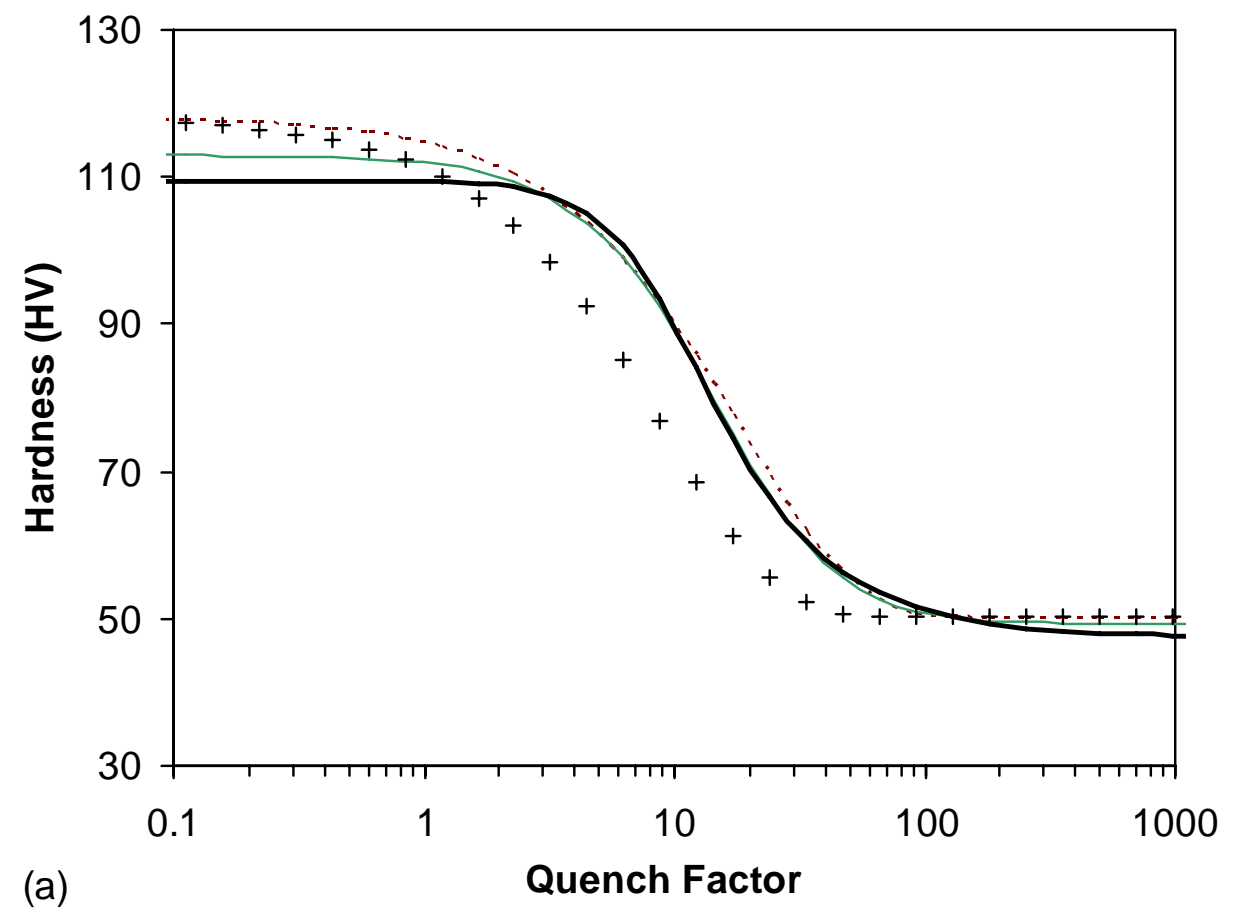

$A-B+C$

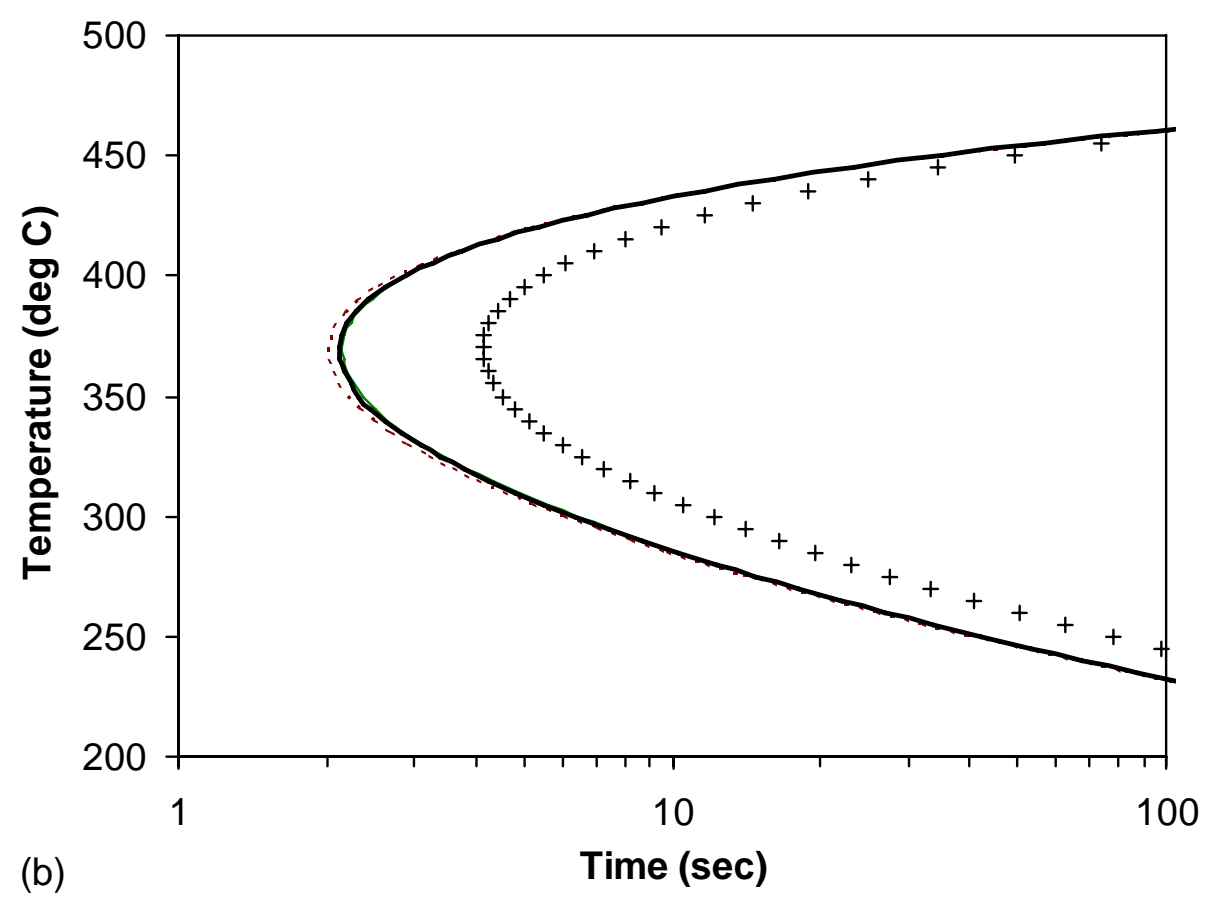

Figure 3: (a) Hardness vs quench factor curves corresponding to (b) $90 \%$ of maximum hardness TTP curves, determined by fitting isothermal 6082 data from Bratland [68] to Eq. 9 for scenarios where $n=1$ (A), $n=1.5$ (B) and $n=2.5(\mathrm{C})$. Scenario D is given by Eq. 5 (classical QFA). Further details are given in Table 3. 


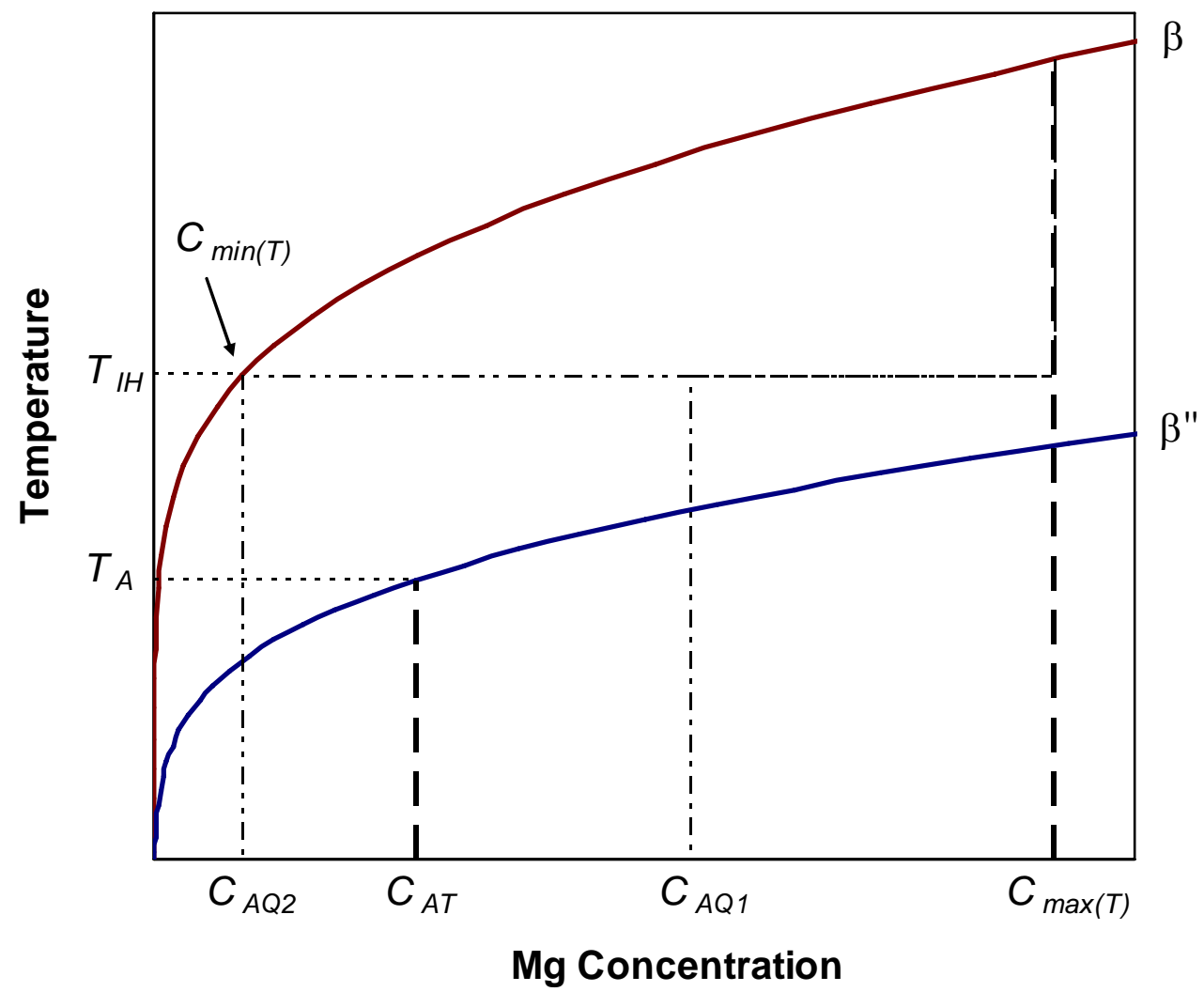

Figure 4: Schematic phase diagram for a 6082 aluminium alloy, showing $\beta$ and $\beta$ " solvii and $\mathrm{Mg}$ concentrations in solution at the solution treatment temperature $\left(C_{\max (T)}\right)$, the ageing temperature $\left(C_{A T}\right)$ and in the as-quenched conditions after quenches 1 and 2 ( $C_{A Q 1}$ and $C_{A Q 2}$, respectively). $T_{I H}$ is the isothermal hold temperature and $T_{A}$ is the ageing temperature. 

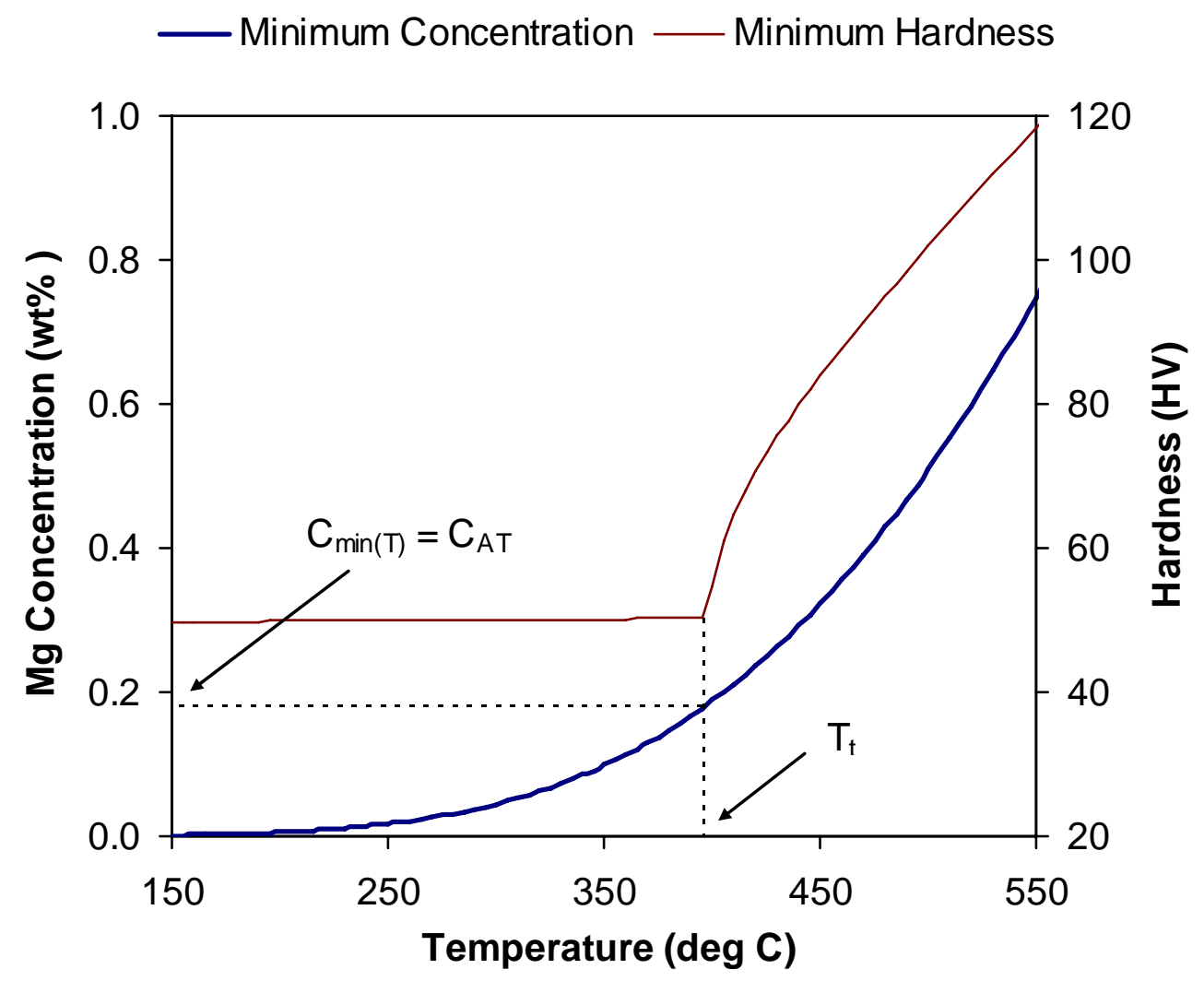

Figure 5: Predicted variation of $C_{\min (T)}$ and $H V_{\min (T)}$ with temperature, based on combined isothermal and continuous cooling 6082 data from Bratland [68]. The transition temperature, $T_{t}$, corresponds to $C_{\min (T)}=C_{A T}$. 
$A-B-C$

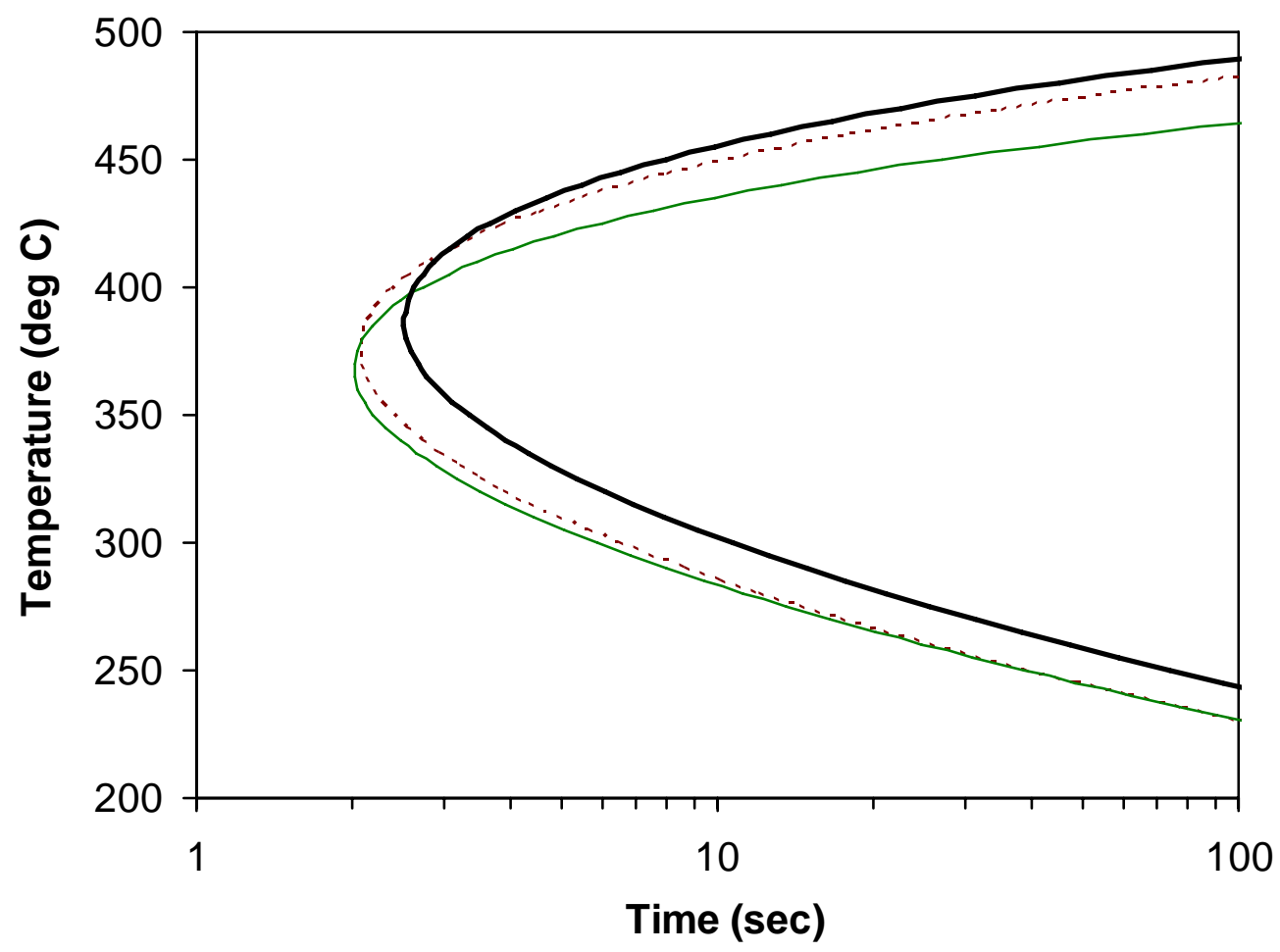

Figure 6: $90 \%$ of maximum hardness TTP curves determined by fitting combined isothermal and continuous cooling 6082 data from Bratland [68] to Eqs. 16 and 17. Details of scenarios A, B and $\mathrm{C}$ are given in Table 4. 